\title{
Characterisation of various geographical origin incense based on chemical criteria
}

\author{
P. Archier and C. Vieillescazes* \\ Laboratoire de Chimie Organique et Analytique, Faculté des Sciences, \\ 33, rue Louis Pasteur, 84000 Avignon, France
}

\begin{abstract}
Incense (or olibanum) comes from different lands of the world. It is sold under several names, which often leads to confusion, in local markets or shops. Authors try to characterise a number of samples according to each geographical origin. Some analytical examples are given. The method is applied to an archaeological sample.
\end{abstract}

Keywords. HPLC - FTIR - incense - olibanum - Boswellia.

\section{Introduction}

The first Egyptologists who looked into the lexical and the botanical texts of ancient Egypt, provided a list of fourteen different species yielding olibanum [1-2]. Nowadays, the several properties of incense continue to confer on it a considerable significance.

Incense, or frankincense in English literature, is also known as oliban in French and luban in Arabic. It is secreted by the bark of some tree species called Boswellia, from the family of the Burseraceae. Twenty-three species of Boswellia occur in East-Africa, India and the south coast of the arabic peninsula, from Dhofar to Aden. According to the literature [3-4-5], four main incense tree species are available, each one being characterised by its geographical localisation:

- Boswellia sacra is located in Arabia but more especially in Yemen (Hadramawt, Dhofar, Mahra). In a way, it is the noble species of its category.

- Boswellia carterii grows in chalky and mountainous areas of Somalia, better known under the name of Mohr. It also exists in Sudan and rarely in Yemen.

- Boswellia frereana appears in Somalia and it is imported in Yemen. In Somalia it is called Yegaar.

- Boswellia bhau-dajiana (local name: Mohr-add) comes from Somalia.

After making an incision in the stem, tear drop secretions appear on the bush and those falling on the ground are collected. Incense or olibanum has a rounded tear shape, halfopaque, a pale yellow colour, and a fragrant and strong smell, with a bitter flavour. The matter is made of between 55 to $70 \%$ of resin, from 25 to $33 \%$ of gum, from 4 to $7 \%$ of essential oil (terpenic components and olibanol) [6-7].
It is only partly dissolved in alcohol, ether and benzene. By steam distillation, only 3 to $8 \%$ of essential oils are available. Finally a thick and whitish smoke with a distinctive smell spreads when incense burns. It has applications in perfumery, pharmacology (as antiseptic), dental and esoteric practising.

Nowadays, it turns out that the term "incense" does not correspond to the original product but has become step by step a generic term, including resins of various vegetal species which have no link to the Boswellia genus.

The aim of this work is to contribute to a better understanding of the gum-resin produced by these species, based on the botanical as well as chemical characterisation. In order to do this, an important number of samples have been studied, including three specimens originating from Yemen; one of them is Boswellia sacra collected by Monod and Bel expedition. Four samples come from Somalia, two from Djibouti, one from Sudan and the last one from India (imprecise tree species).

\section{Techniques and equipment}

The techniques used, apart from the preliminary trials of solubility and determination of the melting point, are high performance liquid chromatography (HPLC), coupled with UVVIS detection (photodiodes array) and Fourier Transform Infrared absorption spectrometry (FTIR).

\section{High performance liquid chromatography}

\section{Equipment}

Photodiode Array detector Waters 991; ternary pump spectraphysics SP 8800; injection loop of $20 \mu \mathrm{L}$, column Merck's Lichrocart cartridge 250-4 Superspher 100 RP-18. 


\section{Original articles}

\section{Chromatographic conditions}

The samples injection is achieved after extraction in methanol (HPLC grade) using ultrasonic bath $(10 \mathrm{~min})$ then filtration on a single use filter (DynaGard $0.2 \mu \mathrm{m}$ ). Elution solvent is made of binary mixture water (A) and methanol (B) at flow rate $0.6 \mathrm{~mL} / \mathrm{min}$.

$\begin{array}{lcc}\text { Gradient (A:B v/v): } & \text { Time(min) } & \text { (A) } \\ & 0 & 80 \\ & 50 & 20 \\ & 120 & 0 \\ & & 0 \\ \text { Fourier transform infrared absorption } \\ \text { spectrometry }\end{array}$

\section{Equipment and analytical conditions}

Fourier Transform spectrophotometer MATTSON serial 1000; FIRST software, 50 scans.

Samples were grounded then analysed with potassium bromide as micropellet (microgram quantities of sample with a 20-fold excess of anhydrous $\mathrm{KBr}$ ).

\section{Results and discussion}

With HPLC (see Tab. I) incenses are characterised, at a retention time close to 78 minutes, by the presence of a compound whose UV spectrum has a maximum at $250 \mathrm{~nm}$. It appears to be a $\beta$-boswellic acid derivative, one of the main constituent of incense. The samples coming from Yemen, except Boswellia sacra, don't give this peak, but show two compounds at retention time of 85 and 90 min- utes, which have the same UV spectrum, according with $\beta$ boswellic acid structure.

In fact (Fig. 1) $\beta$-boswellic acid or $(3 \alpha, 4 \beta)$-3-hydroxyurs-12-en-23-oic acid (structure I) occurs as the acetate (structure II) in frankincense [8]; the $\beta$-form is predominant. It is accompanied by 11-keto $\beta$-boswellic acid (structure III) [9-10]. Moreover, all the chromatograms show in the 7080 min retention time area, the presence of another characteristic compound $(\lambda \max =250 \mathrm{~nm})$ also present in standards of $\alpha$ - and $\beta$-amyrin (Extrasynthese). Furthermore, samples from Yemen (except Boswellia sacra), give two main peaks at 102 and 108 minutes, $\lambda \max =205 \mathrm{~nm}$, which are absent in the somalian, sudanese and indian incenses.

Finally, incense samples from Yemen have no absorbent compounds at $313 \mathrm{~nm}$, whereas one notes their abundance in the Somalia and India incense, which is a main difference.
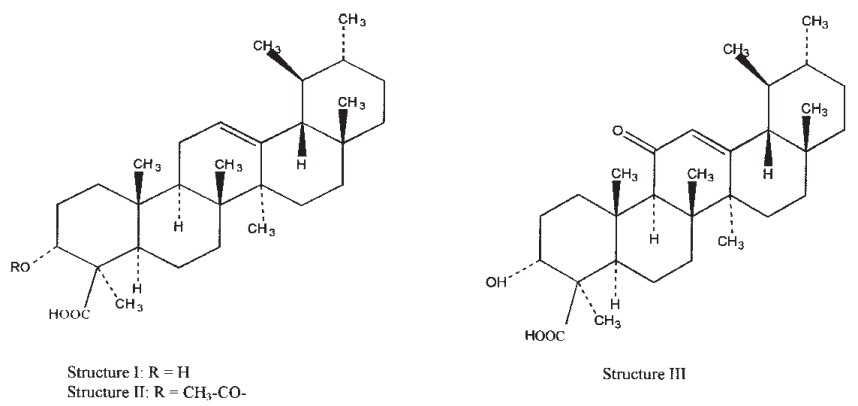

Figure 1. Examples of $\beta$-boswellic acid structures.

Table I. HPLC characteristics with photodiodes array detection.

\begin{tabular}{|c|c|c|c|c|c|}
\hline $\begin{array}{l}\text { Compounds } \\
\text { Name / origin }\end{array}$ & & $\begin{array}{c}\text { TR } 70 \min \\
\lambda \max =204-226-276 \mathrm{~nm}\end{array}$ & $\begin{array}{c}T R 78 \min \\
\lambda \max =250 \mathrm{~nm}\end{array}$ & $\begin{array}{c}T R 80 \min \\
\lambda \max =313 \mathrm{~nm}\end{array}$ & $\begin{array}{l}T R 102-108 \mathrm{~min} \\
\lambda \max =205 \mathrm{~nm}\end{array}$ \\
\hline 1-Yemen incense & Sanaa market & $\mathrm{x}$ & - & - & $\mathrm{x}$ \\
\hline 2-Luban Helw & Sanaa market & $\mathrm{x}$ & - & - & $\mathrm{x}$ \\
\hline 3- Boswellia sacra & Yemen & - & $\mathrm{x}$ & 0 & - \\
\hline 4- Fouh to burn & Djibouti market & $\mathrm{x}$ & $\mathrm{x}$ & 0 & 0 \\
\hline 5- Fouh to chew & Djibouti market & $\mathrm{x}$ & $\mathrm{x}$ & 0 & 0 \\
\hline 6- Olibanum WD1 & Somalia & $\mathrm{x}$ & $\mathrm{x}$ & $\mathrm{X}$ & 0 \\
\hline 7-Olibanum ungraded & Somalia & $\mathrm{x}$ & $\mathrm{x}$ & $\mathrm{x}$ & - \\
\hline 8- Incenso & Somalia & $\mathrm{x}$ & $\mathrm{x}$ & $\mathrm{x}$ & 0 \\
\hline 9- Kouben & Somalia & 0 & $\mathrm{x}$ & $\mathrm{x}$ & 0 \\
\hline 10- Sudan & Sudan & - & $\mathrm{x}$ & $\mathrm{x}$ & - \\
\hline 11- India & India & - & - & $\mathrm{x}$ & - \\
\hline 12- Jerusalem & commercial name & $\mathrm{x}$ & $\mathrm{X}$ & $\mathrm{x}$ & - \\
\hline 13- Nazareth & commercial name & - & $\mathrm{x}$ & $\mathrm{x}$ & - \\
\hline 14- Vatican & commercial name & - & $\mathrm{x}$ & $\mathrm{x}$ & - \\
\hline 15- Liban & commercial name & 0 & $\mathrm{x}$ & $\mathrm{x}$ & - \\
\hline 16- G14 & archaeological sample & - & $\mathrm{x}$ & 0 & - \\
\hline
\end{tabular}

Caption: $\mathrm{x}$ : present compound; -: vacant compound; 0: no interpretable answer (poor signal) 


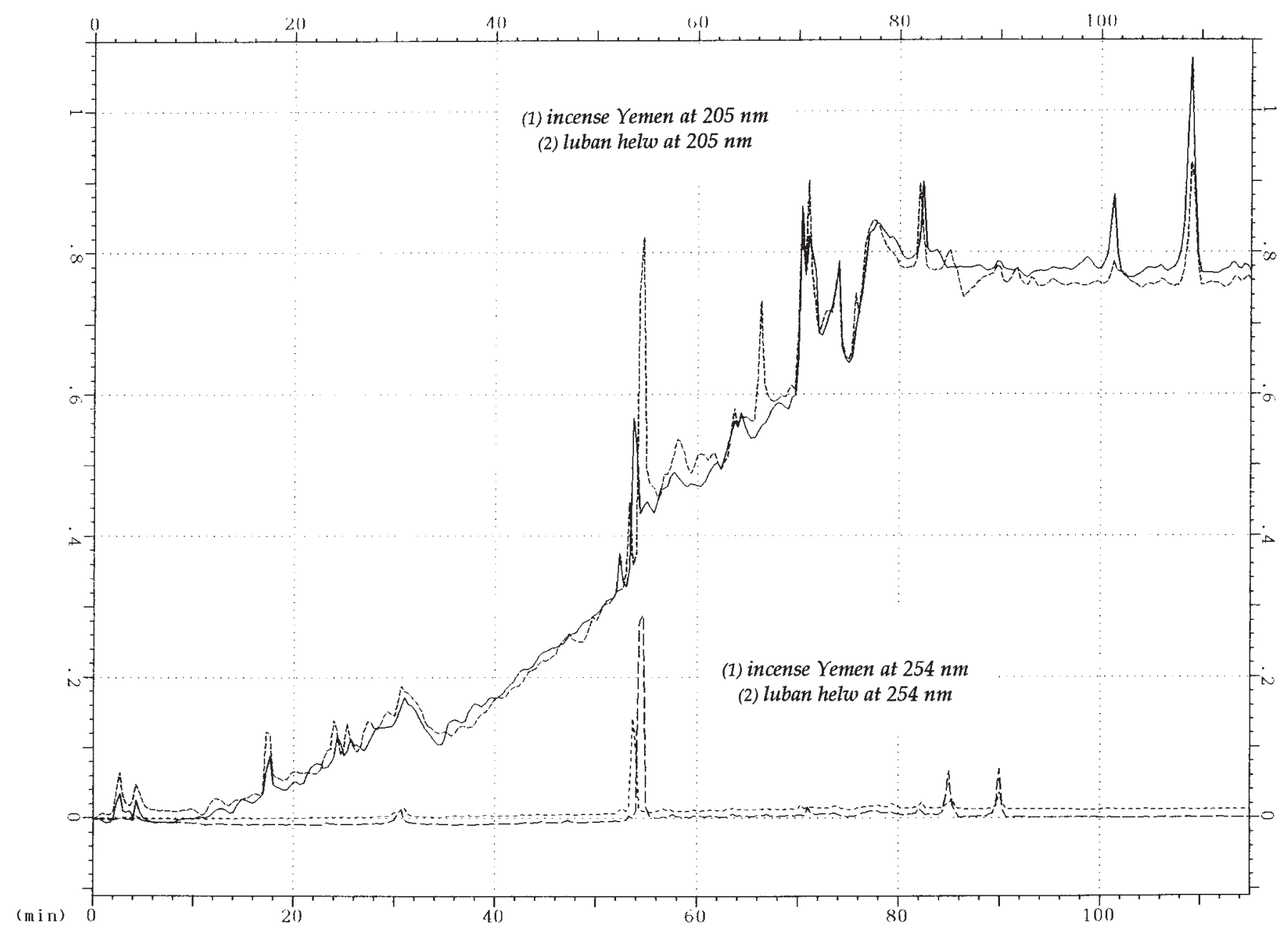

Figure 2. Luban Helw (sample $n^{\circ}$ ) and Yemen incense $\left(n^{\circ} 1\right)$ chromatograms superposition at 205 and $254 \mathrm{~nm}$.

Talking about infrared spectroscopy, there are noteworthy differences of incenses due to their varied geographical origins [11-12-13].

Indian incense is distinguished from the other samples in the $450-900 \mathrm{~cm}^{-1}$ range scale, in particular by the 779 , $692 \mathrm{~cm}^{-1}$ intense bands and most of all by the $459 \mathrm{~cm}^{-1}$.

Sudanese incense seems to be akin to the Somalian incense. Both have an absorption band which corresponds to $\gamma(\mathrm{C}=0)$, in common with Yemen incense; note in the case of Boswellia sacra, two bands at 1741 and $1716 \mathrm{~cm}^{-1}$ are observed. More intense and broader bands in the $1660 \mathrm{~cm}^{-1}$ permit us to recognise it from the Yemen incense. At last, Yemen incense is characterised by a series of narrow 1069, 990,802 and $548 \mathrm{~cm}^{-1}$ bands.

\section{Conclusion}

The results as a whole allowed us to attain the following applications:
- An unknown sample sold on the Sanaa market, under the name of Luban Helw has been unequivocally identified as incense from Yemen. Figure 2 shows the superposition of the HPLC chromatograms at two characteristic wavelengths; figure 3 corroborates the result by IR.

- Two samples bought on the market in Djibouti and called Fouh (one destined to be burnt, the other to be chewed) are similar to a Somalian incense. Figure 4 illustrates by their IR spectra this identification.

- A counter-example is revealed by a sample sold under the name of Mour on the market in Djibouti; it is in fact myrrh. Figure 5 shows the comparison between Mour's IR spectrum and a myrrh standard.

- Finally the products found in the trade under varied appellations (Vatican, Jerusalem, Nazareth...) are characterised by an important presence of $313 \mathrm{~nm}$ absorbent compounds; this criteria permits us to locate their origin in the area of Somalia-Sudan. One also notes, using 


\section{Original articles}
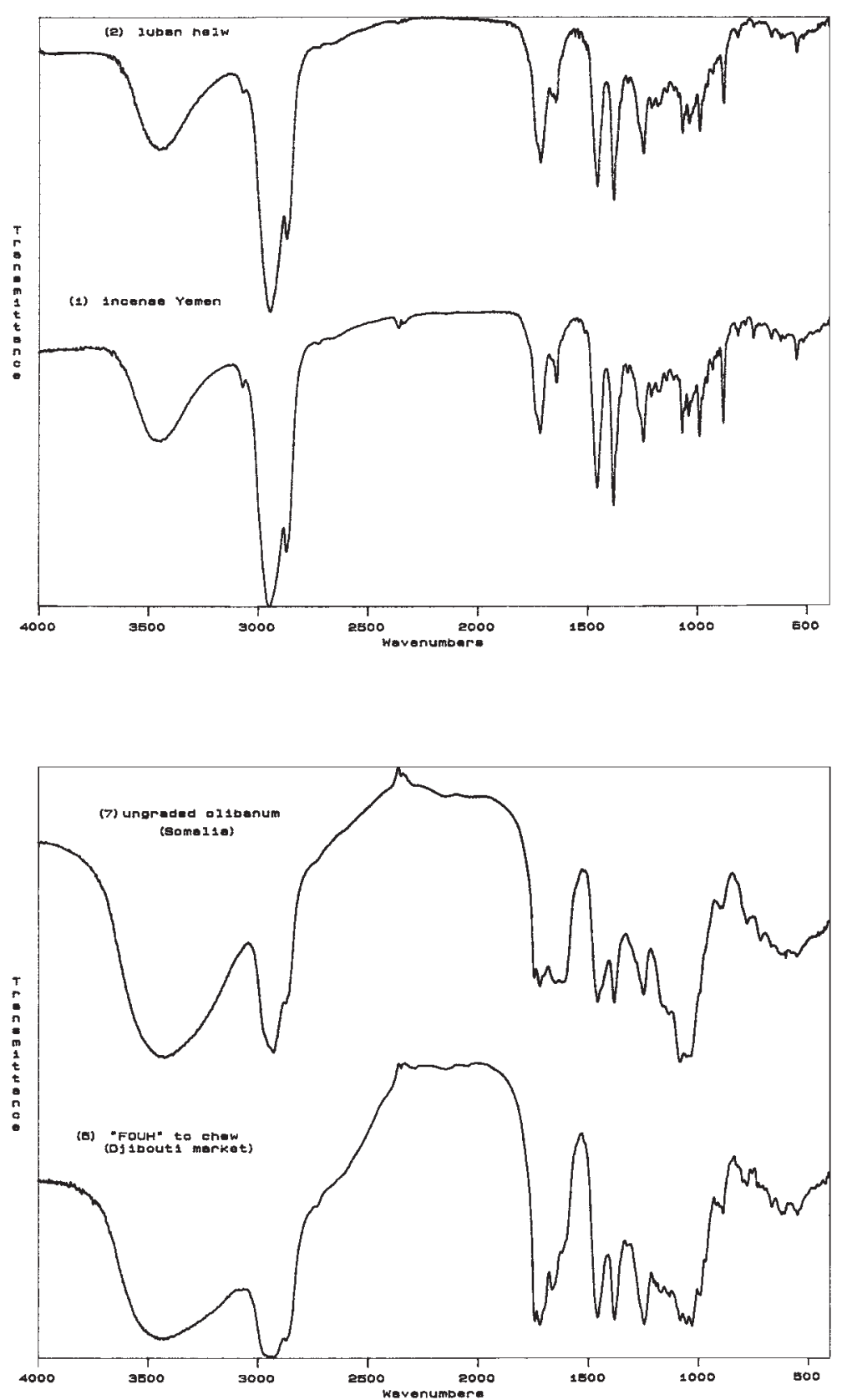

Figure 3. Luban Helw $\left(\mathrm{n}^{\circ}\right.$ 2) and Yemen incense $\left(n^{\circ} 1\right)$ FTIR spectra.
Figure 4. comparison of Fouh $\left(n^{\circ} 5\right)$ and Somalia incense $\left(n^{\circ} 7\right)$ FTIR spectra.
HPLC results, the presence of compounds which could be seasoning and colouring additives.

- A number of studies of archaeological frankincense has been already reported [14-15]. Our method proved to be useful for an analysis of an archaeological sample; an ancient resin (G14: Hekaemsaf's mummy, Saqqarah, Saite time, 660-526 B.C.) has been identified as incense, especially somalian incense.

\section{Acknowledgements}

The authors want to particularly thank J.M. Bel and Th. Monod as well as the Descoins factory (Marseille, France) for their help for this work.

\section{Références}

1. Chermette, M.; Goyon, J.C. Studien zur Altagyptischen Kultur 1996, 23, 47-82. 


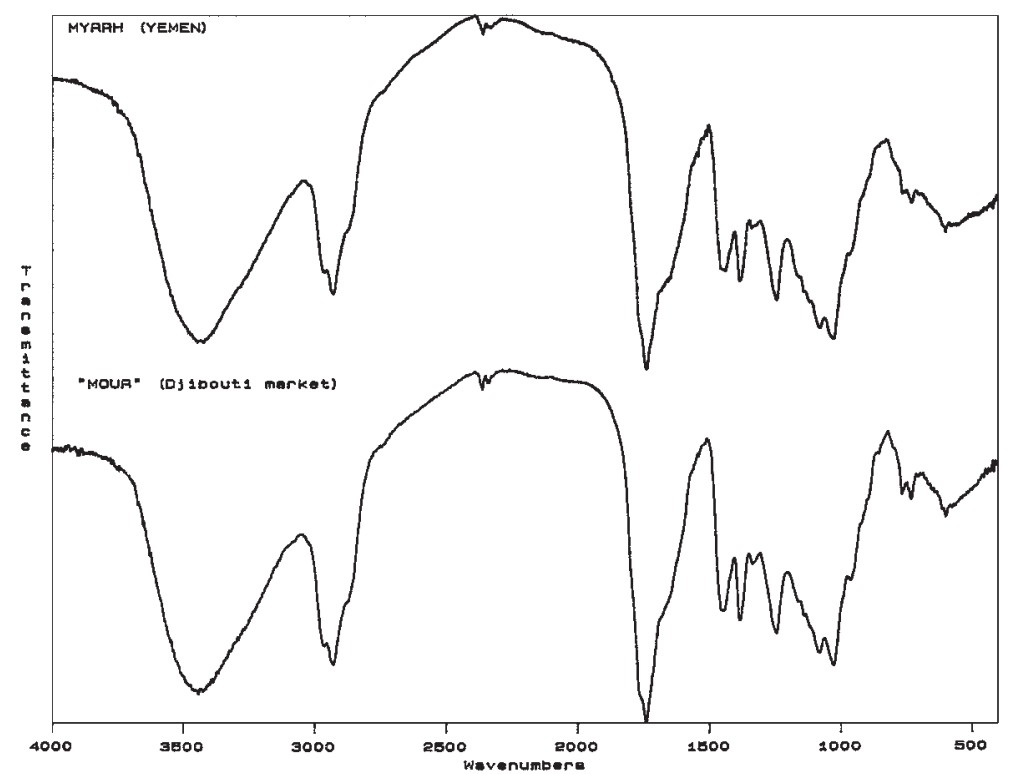

Figure 5. Comparison of Mour and myrrh standard FTIR spectra.
2. Faure, P. Parfums et aromates de l'Antiquité; Fayard: Paris, Collection Pluriel, 1996, 30-35.

3. Monod, T.; Bel, J.M. Botanique au pays de l'encens; Amyris: Bruxelles, 1996.

4. Chadefaud, M.; Emberger, L. Traité de botanique systématique, tome II; Masson: Paris, 1960, 634-639.

5. Gohar Khan; Farooqi, M.I.H. International Journal of Pharmacognosy 1991, 29 (4), 302-305.

6. Abdel Wahab, S.M; Abutabl, E.A.; El-Zalabani, S.M.; Fouad, H.A.; De Pooter, H.L.; El-Fallaha, B. Planta medica 1987, 382-384.

7. Technical notes; Anselmes Establisment "Gums and resins", Marseille.

8. The Merck Index, twelfth edition, 1996.
9. Savoir, R.; Tursch, B.; Huneck, S. Bull. Soc. Chim. Belges 1967, 76, 368-370.

10. Vieillescazes, C. Contribution à la connaissance des matériaux résineux utilisés en Égypte Ancienne; caractérisation par CLHP et spectroscopie, thesis, Avignon, 1992.

11. Bellamy, L.J. The infra-red spectra of complex molecules; Methuen and Co Ltd: London, 1954.

12. Vieillescazes, C.; Archier, P.; Coen, S. Analusis 1997, 25, n³.

13. Edwards, H.G.M.; Falk, M.J. Spectrochimica Acta 1997, 53, 2393-2401.

14. Evershed, R.P.; van Bergen, P.F.; Peakman, T.M.; LeighFirbank, E.C.; Horton, M.C.; Edwards, D.; Biddle, M. Kjolbye-Biddle, B.; Rowley-Conwy, P.A. Nature 1997, 390, 667-668.

15. Van Bergen, P.F. et al. Tetrahedron Letters 1997, $38 \mathrm{n}^{\circ} 48$. 